\title{
Kundalini yoga as mutual recovery: a feasibility study including children in care and their carers
}

\author{
Elvira Perez Vallejos, Mark John Ball, Poppy Brown, David Crepaz-Keay, Emily Haslam-Jones \\ and Paul Crawford
}

The authors affiliations can be found at the end of this article.

Received 24 November 2015 Revised 26 February 2016 Accepted 7 June 2016

() Elvira Perez Vallejos. Published by Emerald Group Publishing Limited. This article is published under the Creative Commons Attribution (CC BY 3.0) licence. Anyone may reproduce, distribute, translate and create derivative works of this article (for both commercial \& non-commercial purposes), subject to full attribution to the original publication and authors. The full terms of this licence may be seen at http:// creativecommons.org/licences/by/ 3.0/legalcode. This study was funded by the AHRC under the large grant ref. $\mathrm{AH} / \mathrm{K} 003364 / 1$

The authors would like to thank all the young people and staff for their participation. This study was funded by the Arts and Humanities Research Council under a large grant titled "Creative Practice as Mutual Recovery: Connecting Communities for Mental Health and Well-being" (AHRC Grant Ref. No. AH/K003364/1).

\begin{abstract}
Purpose - The purpose of this paper is to test whether incorporating a 20-week Kundalini yoga programme into a residential home for children improves well-being outcomes.

Design/methodology/approach - This is a mixed methods feasibility study. Feasibility was assessed through recruitment and retention rates as well as participants' self-report perceptions on social inclusion, mental health and well-being and through semi-structured interviews on the benefits of the study. Mutual recovery entailed that children in care (CIC), youth practitioners and management participated together in the Kundalini yoga sessions.

Findings - The study initially enrolled 100 per cent of CIC and 97 per cent (29/30) of eligible staff. Attendance was low with an average rate of four sessions per participant $(S D=3.7$, range $0-13)$. All the participants reported that the study was personally meaningful and experienced both individual (e.g. feeling more relaxed) and social benefits (e.g. feeling more open and positive). Pre- and post-yoga questionnaires did not show any significant effects. Low attendance was associated with the challenges faced by the children's workforce (e.g. high levels of stress, low status, profile and pay) and insufficient consultation and early involvement of stakeholders on the study implementation process.

Research limitations/implications - Because of the chosen research approach (i.e. feasibility study) and low attendance rate, the research results may lack generalisability. Therefore, further research with larger samples including a control or comparison group to pilot similar research questions is mandatory.

Practical implications - This study has generated a number of valuable guiding principles and recommendations that might underpin the development of any future intervention for $\mathrm{ClC}$ and staff working in children's homes.

Social implications - The concept of togetherness and mutuality within residential spaces is discussed in the paper.

Originality/value - The effects of Kundalini yoga have not been reported before in any peer-review publications. This paper fulfils an identified need (i.e. poor outcomes among ClC and residential staff) and shows how movement and creative practices can support the concept of mutual recovery.

Keywords Mental health, Social inclusion, Well-being, Mutual recovery, Children in care, Kundalini yoga Paper type Research paper

\section{Introduction}

Children are looked after by local authorities for various reasons, including abuse, neglect, challenging behaviour, breakdown of family relationships, homelessness and disability (Department for Education (DfE), 2012). Corporate care is far from perfect, with cumulative evidence showing that children in care $(\mathrm{CIC})$ are still among the most vulnerable children in
\end{abstract}


society. Within the UK, outcomes following local authority care have improved in the last ten years but are still poor and research has shown that $\mathrm{ClC}$ still have higher physical and mental health needs than their not-in-care counterparts (Department for Education (DfE), 2014) and in comparison with children who are in other forms of care such as family foster care (Lee et al., 2011). CIC are more likely to have special educational needs (SEN; 66 per cent have a statement of SEN), poor educational performance, more contact with the criminal justice system, poorer health and greater vulnerability to homelessness and unemployment (DfE, 2014; National Audit Office, 2014). Only half of CIC have emotional and behavioural health that is considered "normal" when using statistical terms (DfE, 2014). Moreover, ClC are substantially overrepresented as both victims and perpetrators of crime (Department for Education and National Care Advisory Services, 2013; Department for Education (DfE), 2013; Centre for Social Justice, 2014). It is difficult to determine, however, the extent to which these outcomes are as a result of experiences prior to entering care or experiences once in the system (Rodrigues, 2004).

One of the contributory factors to this disadvantage may be workforce skills. A report produced by the Expert Group (DfE, 2012) on the quality of children's homes highlighted the main issues facing the workforce as: insufficient levels of qualification, specialist knowledge and skills; inadequate career pathways and progression routes; a lack of reward and recognition; and a lack of identity or shared core professional standards. A recent research report commissioned by the Department for Education (DfE) (2015) and co-produced with a series of stakeholders, including $\mathrm{CIC}$ and children's home staff, has explored the qualifications, skills and training required to meet the needs of CIC. This, together with the latest OFSTED (2014) report, have highlighted a series of recommendations to improve the quality of care and staff (i.e. youth practitioners) working in children's residential care. These recommendations include training on techniques for improving practice and new methods for working with children and young people as well as procedures for working in a children's home.

Another factor affecting outcomes for $\mathrm{ClC}$ is the problems children have with forming relationships. Children's responses to staff may well be influenced by previously damaging interactions with adults. This is known to have an impact on both initial attachment and the ability to form trusting relationships over time (Golding et al., 2006; Hughes, 2004; Thomas and Johnson, 2008). This may partially explain why some forms of therapy are not as readily accepted or engaged with, particularly those which rely on relationships of trust to be effective, which include most psychological interventions. A review of the literature pertinent to looked after children's views of mental health services (Davies and Wright, 2008) identified ambivalence towards professional intervention, noting that children "felt wary of professionals and uncared for"; and ambivalence towards talking. The review concludes that "research suggests that the therapy type (e.g. cognitive-behavioural therapy, family systemic therapy) is less important, rather the experience of being heard and understood could be the foundation for a good match between a child's need for action and therapeutic responsiveness" and that "eliciting looked-after children's views of their mental health service should be standard practice: both in individual treatment and in service development discussions".

This is consistent with policy and practice developments that have put greater emphasis on services user involvement in mental health services. This remains an important part of government policy, with the 2010 White Paper, "Equity and excellence: liberating the NHS" (Department of Health, 2010), making the explicit statement "no decision about me without me", which is adapted from a phrase widely used in the disability movement and one used in patient and public involvement in England for over ten years (Gillbert, 2003). Service user involvement is widespread across health and social care services in the UK (Simpson and House, 2003) but it is clear that this is less widespread in service for CIC (Davies and Wright, 2008).

Local authorities usually explore different alternatives (e.g. foster care) before placing children in residential care, which is often perceived as "last resort" and there has been a steady decline in the use of children's homes since the 1970s. In 1978, 32 per cent of CIC were living in a children's home, secure unit or hostel (Berridge et al., 2012) compared to 9 per cent in March 2012 (DfE, 2013). In addition, children's home have, for the most part, become small group settings. This can be characterised as a move from dependence to independence, and reflects developments in all areas of social care in the UK. Although the move from dependence to independence has 
been widely (in fact, almost universally) welcomed, it is not without its problems. In particular, the focus on the individual and their condition or diagnosis remains on people's illness, impairment or, put bluntly, deficit. We have started to consider independence as a necessary, but temporary, stepping stone towards interdependence. Interdependence recognises the reality that, though we may be individuals, we all rely to a greater or lesser extent on one other. We have noted above that for support for $\mathrm{CIC}$ to be effective, the condition of the relationships between people is as important as the condition of the individual (Davies and Wright, 2008). This narrative moves our thinking from people lumped together as a single problem to people as a collection of individual problems and as a whole community that can provide both problems and solutions (Crepaz-Keay et al., 2015).

In order to address the inequalities and high levels of mental health needs of $\mathrm{CIC}$, it is, therefore important to deal with a number of key factors including improving workforce skills, giving a stronger voice to $\mathrm{ClC}$, building positive relationships between staff and $\mathrm{ClC}$ and improving trust relationships through creative approaches to therapeutic interventions. In short, a more mutual, reflective and collaborative approach may be productive. This includes promoting reflective practice in the workplace, for example, thinking critically about one's contribution, to enhance personal professional development and improvement (Jasper and Rosser, 2013). Several models for reflective practice have been proposed to facilitate staff engaging in a process of continuous learning (Paterson and Chapman, 2013). A key component involves taking a conscious and mindful look at emotions, thoughts, actions and responses, and using that information to reach higher levels of understanding about the personal professional experiences of staff.

We contend that the desirable personal attributes that both $\mathrm{CIC}$ and staff identified as core qualities important among those working in residential child care. These qualities included: being caring, physically agile (i.e. active and sporty), calm, patient, non-judgemental (in-tune with young people), positive and cheerful. These specific qualities are central for the promotion of human health and well-being and are the focus of a study of the nascent discipline of Health Humanities (Crawford et al. , 2015) which provides a robust framework for bringing more creative practices to current health and care settings.

\section{Creative practice as mutual recovery}

This feasibility study was framed under the notion of creative practice as mutual recovery, the idea that shared creativity, collective experience and mutual benefit can promote resilience in mental health and well-being among communities that traditionally have been divided (e.g. children's home staff and $\mathrm{CIC}$ ). Mutual recovery (Crawford et al., 2013) has its roots in the increasingly influential notion of "recovery" in mental healthcare, and refers to the possibility of achieving a meaningful and more resilient life irrespective of mental health "symptoms" or disabilities. Mutual recovery is, by definition, a reciprocal relationship in which all members - service users, residents, professionals, clinicians and everyone else involved - benefit together. Traditionally, recoverybased interventions tend to focus almost exclusively on treating service users, failing to address the high levels of "burnout" and work-related stress among informal carers, and health practitioners (Arber and Venn, 2011; Veage et al., 2014). Mutual recovery challenges the traditional recovery model as an individualised and unidirectional process by promoting spaces where interventions are experienced together. Enacting togetherness is an important relational concept within mutual recovery (Nyman et al., 2012). By engaging in creative practices with someone else, we are expecting the participants to gain access to, and become part of an unfolding enacted narrative that could improve the relationships that form in residential children homes.

Taking into consideration the personal attributes and core qualities that $\mathrm{CIC}$ identified as important among residential staff (i.e. physically active, positive, calm), the systematic poor outcomes reported within $\mathrm{CIC}$ populations and the high levels of stress experienced by residential staff and management working in children's home, we proposed a creative practice - Kundalini yoga - for bringing together a diversity of people, including management, youth practitioners and $\mathrm{CIC}$, to establish and connect communities in a mutual or reciprocal fashion to enhance mental health, well-being and social inclusion among all stakeholders. 
One of the benefits of yoga over other physical exercise or creative therapies is that it gives a sense of connectedness to the self and others, facilitating healthier relationships and a sense of togetherness which is a need expressed by the caring staff of these homes.

\section{What is yoga?}

In the Sutras (Bryant, 2009), Patanjali describes yoga as "calming the fluctuations of the mind stuff". That is to say that the goal of yoga is to calm the mind and affect the way we not only think, but also how we interact with the world. Through asana (yoga postures) and pranayama (control of the breath) we can positively affect our lives and interactions with others.

\section{What is Kundalini yoga?}

Yoga means union. Originally designed as a preparation for the body for meditation, it has become, in modern times, well recognised for the ability to de-stress, and improve many mental and physical conditions. Yoga is a non-pharmacological intervention with few if any adverse effects (Cramer et al., 2013) and can be practised both in groups and individually. Yoga is highly versatile and offers a valuable self-help tool that can be adjusted and tailored to individual needs (Vorkapic and Range, 2014). Cumulative evidence documenting the therapeutic benefits of yoga has grown considerably in the past few years with more healthcare practitioners drawing attention to these more contemplative Eastern practices, including tai-chi and meditation. For example, the British National Health Services recommends the practice of mindfulness to treat stress, anxiety and depression. Not only has the quantity of studies increased but the quality of the research has improved exponentially, now including controlled trials and active control groups (Khalsa, 2004). The positive benefits of yoga have been reported in studies tackling several mental health issues such as depression, sleep disorders, anxiety and panic disorder (Balasubramaniam et al., 2012; Khalsa, 2013; Varambally and Gangadhar, 2012; Deepak, 2013). The study of yoga as a complementary therapeutic intervention has also been proven successful in the treatment of insomnia (e.g. Larouche et al., 2015) as well as a main therapeutic intervention in effectively reducing stress (Smith et al., 2007; Michalsen et al., 2005; Malathi and Damodaran, 1999; Esch et al., 2003), anxiety (Sahasi et al., 1989; Vahia et al., 1973; Sharma et al., 1991; Broota and Sanghvi, 1994; Oken et al., 2006; Kjellgren et al., 2007; Javnbakht et al., 2009), depression (Oken et al., 2006; Michalsen et al., 2005), and stress-related symptoms such as hypertension and insomnia (Smith et al., 2007). Relevant for this study is the work of Conboy et al. (2013) showing that amongst a group of high school students there were many reported benefits of the regular practice of yoga, such as improved self-image, posttraumatic stress disorder symptoms and the propagation of optimism about life challenges (Clark et al., 2014; Rhodes, 2015).

Kundalini is a more dynamic type of yoga with a special focus on breath and movement that works predominantly on the glands and nervous system. It differs from other more classical styles of yoga where quiet still postures are predominant. Called by practitioners, "the yoga of awareness", Kundalini yoga includes repetitive vocalisations (i.e. chanting), breathing exercises (i.e. pranayama and breath of fire), yoga postures (i.e. asana) and meditation to facilitate a calmed and relaxed state of mind and body. This approach is much more suitable for those who have high levels of anxiety or trauma as it gives "hooks" for the mind, keeping the practitioner occupied with following the rhythms of the practice. When the nervous system is over taxed due to stress, coming to a quiet still place requires a physical release provided by combining challenging physical fitness with dynamic meditations. When practiced in a secular way, Kundalini merges traditional mantras with uplifting fun music whilst stimulating the "feel good" brain chemistry. This combination improves relationships (e.g. sense of connection to others and self), promoting compassionate thinking, and attentional focus. Practised regularly over an extended period of time, these changes in perception have the potential to affect the approach to life of participants in positive and profound ways (Castro, 2015).

This study assesses the feasibility of whether a more dynamic, fun and physical type of yoga can improve well-being, mental health and relationship outcomes on children living in a residential home. We hypothesise that this type of embodied practice will be more appealing than 
conventional therapy or other forms of treatment that may lack the physicality and dynamism present in Kundalini yoga. Although there have been non-controlled studies of the effects of yoga in children's homes, we reasoned that this type of yoga could have beneficial effects in a setting where psychological functioning is often low and the frequency of impulsive behaviour high. The idea that you are affected by your environment and the people around you informs the approach of "mutual recovery" and the need to include formal/informal carers in the recovery process, who also experience high levels of stress while caring for traumatised individuals. Children's homes bring an unprecedented opportunity to re-think responses to mental health distress and well-being through the arts and humanities, specifically under the framework of "creative practices as mutual recovery".

\section{Methodology}

The feasibility of a mixed methods study was evaluated according to the following: recruitment and retention rates, self-report questionnaires and semi-structured interviews. The study was conducted from November 2013 to July 2014 and participants were recruited from a private residential provider comprising three children's homes situated within the East Midlands region of the UK. The three children's homes were rated by the national inspectorate, OFSTED, in 2013 as adequate, good and outstanding, respectively.

Recruitment was considered at three initial meetings with management to inform them about the study, followed by two more meetings to inform youth practitioners and $\mathrm{ClC}$. The research was verbally explained to all stakeholders and recruitment packs were distributed containing a letter for prospective participants, a study information sheet, a consent forms and a demographic questionnaire. Ethical approval and oversight was undertaken by the School of Medicine at The University of Nottingham (UK). The only inclusion criterion was the willingness to participate in the research protocol and yoga sessions. There was no exclusion criterion.

The style of yoga was based on a secular version of Kundalini yoga. The programme was delivered via a 20-lesson-plan and included postures, breathing exercises, chanting, dancing and meditation techniques. Each 44-60 min session was generally structured to include warming up, one or two periods of meditation or rest combined with physical movements ranging from warm ups to a peak session of dancing, running, shaking and squats, combined with some static postures, cooling down, 10 min of relaxation, and ending with 3-5 min of meditation. In some aspects it resembles the newly popular interval/intensity training (Buchheit and Laursen, 2013) in that there are short bursts of intense activity, but this is combined with the benefits of mindfulness and meditation which balance the elevating effect of exercise.

Certificates of attendance (see Appendix 1) were offered to all CIC, a £10 gift voucher was offered to the two $\mathrm{CIC}$ with best attendance rates.

Immediately before and after the 20-week yoga programme (see Table I), a trained researcher administered the children versions of self-report questionnaires designed to assess well-being with the Warwick-Edinburgh Mental Health Well-being Scale (WEMBWS; Appendix 2) and social inclusion (Appendix 3) to $\mathrm{CIC}$ and the adult versions of those same questionnaires, plus the General Health Questionnaire (GHQ-12, Appendix 4 designed to assess mental health to staff). Completion of questionnaires took 15 min while completion of the recruitment pack took an average of $20 \mathrm{~min}$.

Table I Description of baseline and outcome measures

\begin{tabular}{|c|c|c|c|c|c|c|}
\hline Outcome measures & Pre-yoga & Post-yoga & $\mathrm{ClC}$ & Staff & Quantitative & Qualitative \\
\hline Demographics & $x$ & & $X$ & $X$ & $X$ & \\
\hline General Health Questionnaire GHQ-12 (Goldberg and Hillier, 1979) & $x$ & $x$ & & $\mathrm{x}$ & $x$ & \\
\hline Well-being WEMBWS (Tennant et al., 2007) & $x$ & $x$ & Short version & Long version & $x$ & \\
\hline Social inclusion (Secker et al., 2009) & $x$ & $x$ & $\mathrm{X}$ & $x$ & $x$ & \\
\hline Treatment compliance & & & $x$ & $x$ & $x$ & \\
\hline Semi-structured interview & & $x$ & $x$ & $x$ & & $x$ \\
\hline
\end{tabular}


The qualitative semi-structured interviews were adapted from Conboy et al. (2013; see Appendix 5). The interviews were conducted within one to three weeks after the administration of the post-yoga session questionnaires. A representative sample of participants $(n=9)$ was selected to participate in interviews via stratified randomisation; strata were gender, status (resident/staff) and children's home $(n=3)$. One interviewer familiar with yoga and meditation was trained to conduct the interviews oneto-one over the phone. When appropriate, interviewers probed participants to retrieve explanations and experiences related to the yoga sessions. Each interview was audio-recorded with participants' permission and took an average of 15-20 min. A thematic analysis was applied. The audio transcripts were first read at least twice and then double coded for themes independently by two of the authors (E.P.V. and M.B.) and any disagreements in coding were addressed in discussion. Coding consisted of searching for sought themes and emergent themes in each transcript, as well as condensing responses to each topic across the sample. We used NVivo v10 and Microsoft Word Office 2010.

\section{Results}

\section{Recruitment and retention rates}

In total, 100 per cent of ClC participated in the study $(n=9)$ and 97 per cent of staff agreed participation (29 out of 30 staff members). Each children's home was constituted by three $\mathrm{ClC}$ and an average of ten staff, including youth practitioners and management. Demographic characteristics for both $\mathrm{ClC}$ and staff are given in Table II. All participants were fluent English speakers.

Participation was low with an average of four sessions per participant attended ( $S D=3.7$, range 0-13). Cumulative results show that four staff never attended any yoga session and only two participants attended a maximum of 13 (see Figure 1 for details).

\section{Self-report questionnaires}

Pre- and post-yoga data from the WEMBWS, social isolation and GHQ showed a normal distribution when applying the Shapiro-Wilk test $(S W=0.99, p>0.1 ; S W=0.96, p>0.06$; $S W=0.96$, $p>0.06$, respectively). Outlier tests (Grubbs and Dixon's $Q$ ratio) were applied to determine if the smallest or larger data value were outliner at 0.05 significant level showing negative results.

Group comparisons within pre-and post-yoga survey were conducted differentiating staff from CIC. Results showed no significant differences between pre- and post-yoga survey (see Table III). From the nine $\mathrm{ClC}$ initial recruited, only five completed the post-yoga questionnaires, while from

Table II Demographic characteristics for the 38 study participants $(n=9 \mathrm{ClC}$ and $n=27$ staff) that enroled in a 20 -week yoga course

Characteristics

Total $C / C n=9$

Total staff $n=29$

Gender
Female

Male

$5(56 \%)$

$4(44 \%)$

Age $( \pm S E)$

$M$

Age range

Ethnicity

African black

Afro-Caribbean

Pakistani

White

Mixed

Time spent at TMC

Weeks ( \pm SE)

M

Range
$14.78( \pm 0.3)$

13-17

\section{0}

0

0

7

2

54.67 (8.7)

14-104
$21(72 \%)$

8 (28\%)

33.07(2.2)

23-68

1

4

2

21

1

$87.21(13.96)$ 11-271 
Total yoga sessions attended

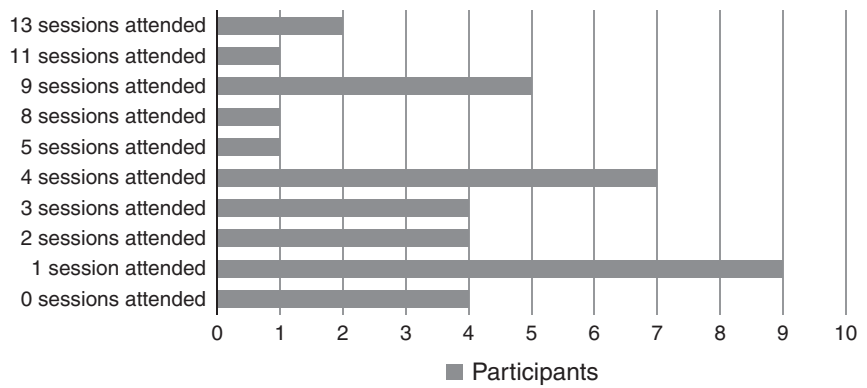

Table III Results from pre-and post-yoga questionnaires analysis among $\mathrm{CIC}$ and staff

\begin{tabular}{|c|c|c|c|c|c|c|}
\hline & \multicolumn{2}{|r|}{ Pre-yoga } & \multicolumn{2}{|c|}{ Post-yoga } & \multicolumn{2}{|c|}{ Differences } \\
\hline & $\mathrm{ClC}$ & Staff & $\mathrm{ClC}$ & Staff & $\mathrm{ClC}$ & Staff \\
\hline General Health Questionnaire & na & $\begin{array}{c}n=29 \\
M=0.91 \\
\text { SD }=0.44 \\
\text { Sum }=10.89(M=5.31)\end{array}$ & na & $\begin{array}{c}n=11 \\
M=0.84 \\
S D=0.40 \\
\text { Sum }=9(M=4.69)\end{array}$ & na & $\begin{array}{c}T=-0.64 \\
p>0.05\end{array}$ \\
\hline Well-being WEMBWS & $\begin{array}{c}n=9 \\
M=2.3 \\
S D=1.17\end{array}$ & $\begin{array}{c}n=29 \\
M=2.52 \\
\mathrm{SD}=0.70\end{array}$ & $\begin{array}{c}n=5 \\
M=2.4 \\
S D=0.4\end{array}$ & $\begin{array}{c}n=11 \\
M=2.76 \\
\mathrm{SD}=0.48\end{array}$ & $\begin{array}{c}T=-0.77 \\
p>0.05\end{array}$ & $\begin{array}{c}T=-0.74 \\
p>0.05\end{array}$ \\
\hline Social inclusion & $\begin{array}{c}n=9 \\
M=1.99 \\
S D=0.49\end{array}$ & $\begin{array}{c}n=29 \\
M=2.42 \\
S D=0.52\end{array}$ & $\begin{array}{c}n=5 \\
M=2.02 \\
S D=0.04\end{array}$ & $\begin{array}{c}n=11 \\
M=2.18 \\
S D=0.11\end{array}$ & $\begin{array}{c}T=-0.96 \\
p>0.05\end{array}$ & $\begin{array}{c}T=-0.39 \\
p>0.05\end{array}$ \\
\hline
\end{tabular}

the 29 staff initially recruited only 11 completed the post-survey questionnaires. Reasons for noncompletion included $\mathrm{CIC}$ leaving the children's home and staff either leaving the children's home (40 per cent of non-respondents) or not returning/completing the paper work (60 per cent of nonrespondents).

Even though the questionnaire showed a tendency for outcome improvement, results did not capture any significant change on well-being and mental health outcomes among CIC and staff. It is worth noting that results from the pre-yoga baseline measures of GHQ indicated that out of the 29 staff that participated in the study, 14 showed clinical symptoms of depression (48 per cent), while out of the 11 staff that completed the post-yoga GHQ, only two (18 per cent) showed clinical symptoms. A more detailed analysis did not show any associations between $\mathrm{GHQ}$ scorings attendance rate or study completion.

\section{Interviews}

The qualitative interviews with both staff and residents were conducted within a month after the administration of the quantitative questionnaires, which occurred within three weeks of completion of the yoga programme in the children's home. A subset of staff and $\mathrm{CIC}$ participating in the study were selected to participate in the interviews via stratified randomisation; strata were children's home allocation, attendance (high vs low), gender and status (staff vs CIC). The interview agenda was an adaptation of Conboy et al. (2013) designed to explore adolescents' perceptions of yoga sessions, including experiences with the study and other changes associated with yoga practice.

Nine study participants completed the interview. This subset included male and female staff and residents from each of the three children's home with different attendance rates. All the study participants randomly selected for interviews agreed to be interviewed. 
Because of the exploratory nature of the semi-structured interview, terms such as "all", "most", "a few" and "one" are used, following the recommendations of Price et al. (2006).

Our findings are grouped into four categories:

1. Individual benefits: participant responses to the practice of yoga postures and breathing techniques, including how they have used these techniques to help themselves in their everyday life. Themes here include mental health (e.g. stress reduction, sleep, emotional regulation, and energy and concentration levels) and physical changes (e.g. back pain, posture improvement, physical awareness and breathing control).

2. Social benefits: transferable techniques learned during the yoga sessions when interacting with others (e.g. feeling more positive and open to others).

3. Recommendation about the design of yoga programmes in children's home: participant's insights concerning induction and introduction to the sessions, yoga implementation, and continuing yoga practice after the study (e.g. location of the sessions and participation rates).

4. Insights into research in children's home: participant's suggestions to improve the implementation of research studies in children's homes. Themes included promoting engagement among $\mathrm{ClC}$ and staff and reducing amount of paperwork.

Individual benefits. Participants reported that the yoga sessions offered beneficial exercises that they used in various contexts, such as before going to bed, emotional challenging times at work as well as at home, and to relieve back pain. Participants reported benefits including physical changes (e.g. increased bodily awareness and body posture) and improved mental health by feeling more energetic, relaxed and calmed.

All participants focussed on the mental and emotional benefits and less on the physical benefits of yoga as an exercise. Correspondingly, benefits reported by these participants focussed more on changes in stress reduction, sleep, energy and concentration levels, and emotional regulation both during and outside the children's home.

Regarding stress reduction, most participants reported positive effects such as feeling able to relax and stay calm. Some staff noticed positive changes on CIC, describing them as quieter and calmer after the yoga sessions:

I felt a lot calmer, felt more ready to be able to deal with the issues (S3).

[...] she does just seem a lot calmer and happy afterwards (S7).

Most participants reported that yoga augmented the quality and duration of their sleep. Many of them used yoga techniques to aid in falling asleep at night:

When I'm going to sleep I use that part at the end when you lie down and have to like, relax, to cool down, I use that when I'm going to sleep and its helps me to go to sleep (S1).

[...] for me sleep was a problem and I don't think it was through exhaustion, and I certainly sleep a lot better now than I did (S9).

Most participants reported an increased ability to observe and control emotions. Many participants indicated a decrease in their tendency to be emotionally reactive and an increase in the ability to witness their own negative feelings with detachment. Some participants indicated a greater sense of self-awareness and focus on their own health:

I felt really good [...] it put quite a lot of things into perspective (S9).

I learnt a lot about myself, I think it's given me far more focus in what I'm doing, I think reflecting and looking back on it regarding focus; it gave me a lot more focus, not just jobwise but life wise [...] I'm happier, I'm certainly happier, and I'm certainly a lot more focussed on my health than I was and I say I'm a lot more focussed on me than I was (S9).

Regards energy and concentration levels, (Kundalini as energy un-blocker), some participants reported feeling more energetic and being able to focus more on their activities:

She seems more happy and energised afterwards (S7).

[...] helped me concentrate (S9).

PAGE 268 JOURNAL OF CHILDREN'S SERVICES $\mid$ VOL. 11 NO. 42016 
Physical changes were also reported. An important principle of yoga is learning how to be fully present in the moment-by-moment experience of being alive. Kundalini yoga uses a combination of dynamic postures and breathing exercises to facilitate body awareness. Some staff found specific stretches helpful for their back pain, posture improvement, physical awareness and breathing control:

"I couldn't do many [asanas] because of my back injury, but what I did do was some of the breathing exercises and things which I found quite good", "breathing and control of breathing" (S8).

[...] yoga's sort of like reignited that interest again [feeling healthy through exercise] [...] I regularly do the exercises at home (S9).

Social benefits: enacting togetherness. Some participants reported direct benefits from practicing yoga with others, and felt more positive, open to others and, as a consequence, an improvement in their social life in and outside work. Some staff and residents noticed that other people interacted more positively with them. For example, on the first day of the programme we scheduled two evening sessions to allocate $\mathrm{ClC}$ and staff from the three children homes (one from $17.00 \mathrm{hrs}$ till $18.00 \mathrm{hrs}$ and the second right after an hour later). One $\mathrm{CIC}$ from the second session complained about being "the only girl" and decided not to join in. A CIC from the first group encouraged her to join and gave her reasons including: "you should not miss it", "it is great", "it is not what you think", "it will blow your mind" and so on. The young person from the first group agreed to repeat the session to accompany and support her friend allocated to the second group. This example captures the generosity and good intentions of the young person from the first group, willing to repeat the session to ensure her friend would experience the similar benefits that she had experienced. In this altruistic example, mutuality is central and it is facilitating relational depth among $\mathrm{ClC}$ as well as acting as role model to staff and other $\mathrm{ClC}$.

Some staff and CIC indicated that practicing yoga together brought new opportunities for engaging in conversations related to the yoga practice and it provided a new topic of conversation and opportunities for being together and supports each other:

[People are more] positive, they will be like 'Oh have you done this or that or the other' and it's more friendly (S1).

I feel more positive and more open (S4).

I mean it did make for a good conversation point because we were all having a good chat about it, what we did there and how, we had a laugh (S5).

They'd come back a bit quieter (S5).

"I have noticed X, who participated the most, who seems a bit more open and a bit calmer afterwards". "She seems more happy and energised afterwards" (S7).

It was nice to sit down afterwards and it was nice that we all chatted around the table and ate dinner together (S7).

My friends are surprised that I probably offer them a few more solutions than I used to, I think my friend circle has probably expanded a bit where l've had friends, but they've not been really meaningful, now I take a little bit more of an interest in what's happening to them and I think that they probably recognise that (S9).

I feel more connected to others (S9).

Certainly patience with the service user, with the children, I've always had, it's always been there, but I think the way I react now to situations with managers is a lot more focussed and not as reactive, I'm pretty much more proactive than I used to be (S9).

Insights on designing yoga programmes in children's home. Bringing yoga into children's home has unique challenges and opportunities. All interviewees found the yoga sessions enjoyable and most describe them as fun, very good and interesting. Most participants enjoyed the relaxing part and highlighted its calming effects as the outcome they enjoyed the most. All interviewees expressed a willingness to continue the sessions. Nobody indicated any suggestions for improvements, keeping the $1 \mathrm{hr}$ weekly sessions as it was delivered, maintaining its content and the format. While most staff indicated that attendance could improve by keeping the session 
in-house, a mixture of responses were found among the residents. Questions of implementation among both residents and staff such as "should sessions be compulsory for staff?" came up during several of the interviews:

[...] it's opened my eyes to something new (S3).

"[...] it was a good way [the yoga teacher] delivered it, with the music and doing lots of different quite short exercise and then the relaxation at the end was always nice", "I thought it was delivered well and when the young people were around and were engaged then everything went really well", "I think the actual yoga itself was quite good", "Yeah, probably [to continue the yoga sessions]" (S4).

I enjoyed it all [...] meditation techniques on how to breathe calmly and diffuse things with breathing (S5).

It was clear, it was definitely clear [...] would not change anything (S8).

Initially, the yoga sessions were offered within each residential setting; however, due to logistic problems, such as the yoga sessions clashing with other after-school activities, participants suggested holding the sessions in a school hall on a suitable date/time to benefit from the larger space and the opportunity to merge all the $\mathrm{ClC}$ and staff within a single venue. Participants also anticipated that an external venue could offer fewer distractions and provide a physical distance from the rather stressful residential settings. Having the yoga sessions within the school premises did not suit one of the children's homes because of the long distance they had to travel and, consequently, it was finally decided to merge only two of the children's homes in a nearby church hall and continue with the in-house yoga sessions for the more outlying children's home. When participants were asked about the location, only one indicated a preference for having the sessions in an external venue, while most of the interviews stated that having in-house sessions could improve attendance:

I think it was great having it in the house, for the kids, it helped who was a little bit nervous of what to do, and rather than her just refusing, she was there and she was witnessing it and she could see all the people that were joining in and that sort of encouraged her to join in as well, I think it would need to remain at the home (S3).

l'd rather be at home [...] Maybe you should try and do it in-house, because then it's more you coming to them instead of us having to try and get the young people out of the house (S5).

Participants reflected on the low participation rates expressing that some staff felt they did not have enough time to attend the sessions or that some CIC were not eager to attend. This meant that the young practitioners supporting those $\mathrm{ClC}$ were also unable to attend. Most staff felt that they had to attend the yoga sessions and this pressure created a barrier for engagement. Some staff felt the rationale for participation was not introduced adequately, especially to those with no previous experience in yoga. Some participants felt there was a lack of ownership, consultation and co-production on the implementation of the yoga study. Most participants reported that they would continue to practice yoga, especially among those that experienced benefits:

“Every time I was at work and it came up usually the young people didn't want to go, every time I tried to talk them into going they wasn't interested really, and as far as during my days off I just never really had time", "I don't really have time at this time", "I wish I would have had time to make it, I really do, it sounds like something that is fascinating to me but I just, with the way things happen in life sometimes you can't do everything you want to do" (S2).

I just wish more people would have participated from the home, the staff at the home you know; I think if we'd had better participation from the staff the kids would have been more inclined to join in, so I found that a bit of a frustration on my part (S3).

Yeah, you're unable to plan for anything, your day shifts so rapidly from one minute to the next, its constant changes and how we adapt to them, and I think when people haven't had that insight into them it's quite an eye opener (S3).

I think it was just probably that they had other activities planned or had their own trust time so they wanted to go out independently on their own and not necessarily to yoga (S5).

It would have been nicer if the kids were more engaged (S6). 
"I think, if was it was sort of more, it was hard for people to get to and hard for people to give up work, and if you're on shift and the kids aren't in a good mood it made it quite difficult for us, and obviously if you'd had a bad shift the day before you didn't feel like coming in, and I think that was one of the main problems, attendance, because we had to fit it in around our shifts and we work such long shifts that it made it quite difficult to staff" [...] "I think if it was more optional then staff would be more willing to take part, I think the fact that we were told it was training and we would get in trouble if we didn't attend sort of upset people before they'd even started" (S7).

Insight into research in children's home. The last set of interview questions queried the participants' experience with the study and the measurement techniques used. The qualitative interview data revealed some areas of weakness and strength in the research design and techniques for working with this population.

On completing self-report surveys and consent forms, all participants reported that they were able to understand the quantitative questionnaires and felt that the questions were straightforward and clear. All reported comfort with asking the researcher for clarifications around the research process. Yet, nearly all of them found the questionnaire and all the study paperwork (i.e. consent forms, information sheets and letters to participants) to involve far too much documentation. Some of them did not feel confident completing the paperwork and found the process "annoying" and "tedious", while some other participants felt the paperwork was necessary for the study. One participant felt there was no enough privacy when completing the self-report questionnaires:

I thought it was a bit of a headache to be honest, it was just a lot of paperwork to fill in, so it's like its already getting you a bit anxious because not everybody may be as confident with paperwork so it's already building up that anxiety for you then to calm it back down with the yoga techniques (S5).

I think you could have made the paperwork less tedious, but obviously paperwork is tedious (S5).

On nature of the context, the following comments illustrate the stressful nature of the children's home environment as well as some personal reflections from members of staff that influenced participation involvement in the yoga sessions:

We're having a bit of a rough ride at the minute and the staff are a bit like "oh no" [...] but for all the bad days we have there's twice as many good days [...], so that's the way you've got to look at it, we go through the bad times but we actually have some really good times with the children and that's important to recognise isn't it (S3).

Disappointed in myself that there were lots of issues going on in the home that sometimes took me a away from being able to do the yoga (S3).

\section{Discussion}

Little is known about the use of Kundalini yoga in children's homes. This mixed methods feasibility study explores the experiences of $\mathrm{CIC}$, youth practitioners and management staff participating together in the treatment arm of a 20-week yoga programme. We asked participants about the practice of yoga, its perceived benefits and their experiences participating in the study. They reported individual benefits (such as stress reduction and better sleep), social benefits (such as feeling more positive and open to others), suggestions to improve the design of future programmes (such as more foregrounded co-construction and stakeholder involvement) and ways of improving the design of the research with this population (such as reducing the amount of the paperwork).

Due to the low engagement rates, participants were asked to offer suggestions for improving the feasibility of the intervention in this context. During the 20-week programme, participants were invited to provide feedback regarding retention rates and suggestions included bringing food for sharing after yoga when the sessions took place outside the children homes (e.g. church hall) or cooking a meal in the children's home and dining together, so promoting the community spirit and also taking advantage of the calm and pleasant feelings experienced right after the Kundalini yoga practice. This suggestion was put into practice and was well accepted, creating a feeling of togetherness and the opportunity to share food with others. 
By engaging in the yoga practice with others, residents and staff gained access to the experiences of others and responses to actions which created spaces for interpretation and empathy. Spontaneous vocalisations (e.g. loud sighs) enhanced the social togetherness and a sense of proximity to others. The yoga sessions were designed as a social activity, as something to be done together. The more dynamic aspects of the yoga practice (e.g. jumping), in combination with the more relaxing parts (e.g. lying down), enhanced the positive effects on physical and mental health while promoting a sense of connectedness to the self and others.

Some of the CIC brought their favourite music tunes to be played during the yoga sessions, promoting ownership and participation. All participants reported liking the yoga programme, not willing to change any aspect of it and a wiliness to continue it.

Importantly, the self-report questionnaires did not capture any statistical change due to high rate of attrition but they did show alarming levels of self-reported clinical depression among the staff. This result emphasises the need to promote mutual recovery in terms of well-being and mental health in children's homes among CIC as well as the staff and confirms the importance of selfcare practices, as well as, raising the profile, status and pay of those who work in children's residential care. It is self-evident that staff in children's homes are working with some of the most vulnerable members of society, yet their pay and status leaves them feeling very undervalued.

Taking into account that positive, good quality interactions between carers and children are key to the success or failure of a residential placement - as they determine whether the environment is one of care or stress (Holden, 2009) - we would postulate that improvements in the well-being of carers as well as children allow for a mutual and reciprocal improvement in well-being. We argue that if residential staff were better equipped emotionally, then the outcomes for children would be enhanced. One route to enhancing well-being is the shared practice of Kundalini yoga, especially when taking into account interviewee statements indicating that they felt more tolerant, less stressed, more patient, open, positive and receptive to $\mathrm{ClC}$ - all attributes perceived as highly desirable by $\mathrm{CIC}$.

To our knowledge, there is only one published study by Kennedy et al. (2013) involving front-line staff alongside the children and this was undertaken in the psychiatric department of a large children's hospital. The study reported in this paper shows that yoga sessions (alongside other arts therapies) improved self-esteem, taught coping skills and provided relaxation among other benefits. Participants reported personal and professional benefits as well as being able to perceive the benefits the patients were getting from the therapy. We must be careful not to generalise the results of this study too widely as it is not possible to isolate the individual impact of the yoga itself as it was part of a wider range of therapeutic activities (music, art, dance/movement); it was also conducted using a sample of children who all suffered from diagnosable mental health disorders, so the outcomes may be different when compared with those of children without a formal diagnosis. The benefits of this mutual recovery approach, where children and staff in residential homes took part in an activity together, is one of the aspects that was explored by our study.

\section{Conclusions and recommendations}

The general conclusion that residential care for children is not ideal, expensive and has few longterm benefits - particularly those who stay for a long time - is supported by many studies and reports (e.g. De Swart et al., 2012; Frensch and Cameron, 2002; Hair, 2005). However, this provision is the "last resort" for approximately 5,000 children in England (DfE, 2014). Viewing recovery as reciprocal opens up new possibilities for examining how recovery for mental health and well-being in children's homes could be enhanced through shared practice between $\mathrm{CIC}$ and residential staff - and through outreach beyond children's homes including education personnel and local community groups - and how creative practice may contribute to this. The perspective of "mutual recovery" challenges current individualised and divided conceptions of recovery within social and health care services and policy, instead seeing it as an interactional, holistic and mutual process where all players are present enacting togetherness, so instigating a more comprehensive and meaningful understanding of the recovery process. Indeed, the study has provided qualitative evidence to suggest that the goal of yoga (i.e. union) has been achieved for the participants of this study as most mentioned feeling more open to others and nearly all of them described the practice as calming and relaxing. 
We found evidence that creative practice as mutual recovery (i.e. the practice of Kundalini yoga in children's home when participation involves both $\mathrm{CIC}$ and staff) is a plausible intervention that can lead to individual and social benefits, even when such gains are not directly prescribed by the yoga programme or captured on the self-report questionnaires. This is an exciting finding for it suggests that yoga practice, in children's homes, especially when participation is high, has the potential to enact togetherness and mutuality and improve health and psychological outcomes for $\mathrm{CIC}$ as well as for the workforce. Consequently, when yoga is practiced in a group, it has the potential to minimise the negative consequences associated to poor outcomes (e.g. higher risk of poor mental health and increased likelihood of being a victim or perpetrator of crime) by promoting emotional and social togetherness.

In order to maximise retention rates, participation and, therefore, potential benefits, a series of suggestions and recommendations can be made. The study has shown that both $\mathrm{ClC}$ and youth practitioners were unsure of whether attendance was prescribed or voluntary, possibly resulting from what participants considered heavy agreement and consent documentation or a presiding top-down decision making within these often challenging environments. Future interventions should promote a horizontal structure (instead of a vertical top-down approach) where equal partnership within CIC, staff, yoga teachers and researchers is celebrated. Working with stakeholders as equal partners is important to guarantee an active and balanced involvement in the designing process and decision making, enhancing participation and ownership. It is essential to co-design strategies and guidelines to maximise the success of any intervention even though this may require more time for planning the intervention. We suggest the creation of a reference group that will include a representative sample of those directly and indirectly involved in the project that should meet several times before any decision is taken to build rapport, trust and leadership. This reference group will discuss potential solutions to known barriers and also participate in a series of workshops to discuss relevant evidence related to the project to improve understanding of the "why" and "what". Implementation strategies should be co-produced with stakeholders to ensure that these are sensitive to cultural differences and relevant to a specific point in time. In this way, interventions co-produced with specific communities will differ from other programmes developed for similar communities as each context is treated as unique.

We also suggest minimising paperwork and providing information verbally to participants, if considered ethically acceptable, and using passive consent and opt-out procedure instead of explicit consent.

Further research should be designed to overcome the methodological limitations of the current study including the relative small number of participants and total number of sessions completed in the intervention, as well as the absence of a comparison or control group (e.g. other group activity). A larger and more representative sample involving several children home providers could allow a better understanding of the numerical findings from the questionnaire measures and a greater focus on mutuality (i.e. the social benefits linked to enacting togetherness). The above recommendations for maximising participation (e.g. creation of a reference groups) will feed the design of a larger pilot study that it is expected to produce a more powerful approach to quantitative data as well as a greater focus on the concept of "mutuality".

\section{Implications for policy and practice}

- Children's residential staff need to be better supported.

- The outcomes for CIC need to improve.

- Children homes are considered "last resort" and this has a negative effect both on the staff and residents.

- Creative practices involving both staff and residents are a cost-effective intervention that has the potential to improve relationships and attachment issues.

- Co-production and reference groups are mandatory to implement these types of practices in residential settings to enhance the sense of ownership and engagement. 


\section{References}

Arber, S. and Venn, S. (2011), "Caregiving at night: understanding the impact on carers", Journal of Aging Studies, Vol. 25 No. 2, pp. 155-65.

Balasubramaniam, M., Telles, S. and Doraiswamy, P.M. (2012), "Yoga on our minds: a systematic review of yoga for neuropsychiatric disorders”, Frontiers in Psychiatry, Vol. 3 No. 117, doi: 10.3389/fpsyt.2012.00117, available at: http://journal.frontiersin.org/article/10.3389/fpsyt.2012.00117/full

Berridge, D., Biehal, N. and Henry, L. (2012), “Living in children's residential homes”, Report No. DfE-RR201, Department for Education, London.

Broota, A. and Sanghvi, C. (1994), "Efficacy of two relaxation techniques in examination anxiety", Journal of Personal Clinical Studies, Vol. 10 No. 1, pp. 29-35.

Bryant, E.F. (2009), The Yoga Sūtras of Patañjali: A New Edition, Translation and Commentary ISBN 0865477361, North Poinnt Press, New York, NY.

Buchheit, M. and Laursen, P.B. (2013), "High-intensity interval training, solutions to the programming puzzle", Sports Medicine, Vol. 43 No. 5, pp. 313-38.

Castro, J.M. (2015), "Meditation has stronger relationships with mindfulness, kundalini, and mystical experiences than yoga or prayer", Consciousness and Cognition, Vol. 35, September, pp. 115-27.

Centre for Social Justice (2014), "Survival of the fittest - improving life chances for care leavers", available at: www.centreforsocialjustice.org.uk/UserStorage/pdf/Pdf\%20reports/CSJ_Care_Report_28.01.14_web.pdf (accessed January 2016).

Clark, C., Lewis-Dmello, A., Anders, D., Parsons, A., Nguyen-Feng, V., Henn, L. and Emerson, D. (2014), "Trauma-sensitive yoga as an adjunct mental health treatment in group therapy for survivors of domestic violence: a feasibility study", Complementary Therapies in Clinical Practice, Vol. 20 No. 3, pp. 152-8.

Conboy, L., Noggle, J., Frey, J., Kudesia, R. and Khalsa, S. (2013), "Qualitative evaluation of a high school yoga program: feasibility and perceived benefits", Explore, Vol. 9 No. 3, pp. 171-80.

Cramer, H., Krucoff, C. and Dobos, G. (2013), "Adverse events associated with yoga: a systematic review of published case reports and case series", PLoS One, Vol. 8 No. 10, p. e75515, doi: 10.1371/journal. pone.0075515.

Crawford, P., Brown, B., Baker, C., Tischler, V. and Abrams, B. (2015), Health Humanities, Palgrave Macmillan.

Crawford, P., Lewis, L., Brown, B. and Manning, N. (2013), "Creative practice as mutual recovery in mental health", Mental Health Review Journal, Vol. 18 No. 2, pp. 55-64.

Crepaz-Keay, D., Fulford, K. and van Staden, W. (2015), "Putting both a person and people first: interdependence, values-based practice and African Batho Pele as resources for co-production in mental health", in Sadler, J., van Staden, W. and Fulford, K. (Eds), The Oxford Handbook of Psychiatric Ethics, Chapter 24, Oxford University Press, Oxford, pp. 60-84.

Davies, J. and Wright, J. (2008), "Children's voices: a review of the literature pertinent to looked-after children views of mental health services", Child and Adolescent Mental Health, Vol. 13 No. 1, pp. 26-31, doi: 10.1111/ j.1475-3588.2007.00458.x.

Deepak, K.K. (2013), "Yogic intervention for mental disorders", Indian Journal Psychiatry, Vol. 55 No. 3, pp. 340-3, available at: www.indianjpsychiatry.org/text.asp?2013/55/7/340/116300

Department for Education (DfE) (2012), "Reform of children's residential care”, Department for Education, available at: media.education.gov.uk/assets/files/pdf/c/childrens\%20homes\%20reform\%20quality\% 20group\%20\%20\%20final\%20report.pdf (accessed 15 September 2015).

Department for Education (DfE) (2013), "Care leaver strategy", Department for Education, available at: www. gov.uk/government/publications/care-leaver-strategy (accessed 15 September 2015).

Department for Education (DfE) (2014), "Outcomes for children looked after by local authorities in England as at 31 March 2014", Department for Education, available at: www.gov.uk/government/uploads/system/ uploads/attachment_data/file/384781/Outcomes_SFR49_2014_Text.pdf (accessed 15 September 2015). 
Department for Education (DfE) (2015), "Training and developing staff in children's home”, Department for Education, available at: www.ncb.org.uk/media/1215591/rr438_training_and_developing_staff_in_children_s_ homes.pdf (accessed 15 September 2015).

Department for Education and National Care Advisory Services (2013), "Key statistics on looked after children and care leavers", Department for Education and National Care Advisory Services, available at: www.publications. parliament.uk/pa/cm201213/cmselect/cmeduc/632/632vw46.htm (accessed 15 September 2015).

Department of Health (2010), "Equity and excellence: liberating the NHS", HMSO, available at: www.gov.uk/ government/uploads/system/uploads/attachment_data/file/213823/dh_117794.pdf (accessed 15 September 2015).

De Swart, J., Van den Broek, G., Stams, J., Asscher, P., Van der Laan, P., Holsbrink-Engels, G. and Van der Helm, G. (2012), "The effectiveness of institutional youth care over the past three decades: a meta-analysis", Children and Youth Services Review, Vol. 34 No. 9, pp. 1818-24.

Esch, T., Fricchione, G.L. and Stefano, G.B. (2003), "The therapeutic use of the relaxation response in stressrelated diseases”, Medical Science Monitor, Vol. 9 No. 2, pp. RA23-34, available at: www.medscimonit.com/ download/index/idArt/4745

Frensch, K. and Cameron, G. (2002), "Treatment of choice or a last resort? A review of residential mental health placements for children and youth", Child and Youth Care Forum, Vol. 31 No. 5, pp. 307-39, doi: dx.doi.org/10.1023/A:1016826627406.

Gilbert, D. (2003), "Nothing about us without us: what patient and public involvement means to CHI”, Quality in Primary Care, Vol. 11 No. 1, pp. 61-5, available at: search.ebscohost.com/login.aspx? direct=trueanddb=cin20andAN=2003157339andsite=ehost-live

Goldberg, D. and Hillier, V. (1979), "A scaled version of the General Health Questionnaire", Psychological Medicine, Vol. 9 No. 1, pp. 139-45.

Golding, K.S., Dent, H.R., Nissin, R. and Stott, L. (2006), "Being heard: listening to the voices of young people and their families", in Golding, K.S., Dent, H.R. and Stott, L. (Eds), Thinking Psychologically about Children Who Are Looked After and Adopted: Space for Reflection, Jonh Wiley \& Sons, Ltd., The Atrium, Southern Gate, Chichester, West Sussex, pp. 1-34.

Hair, H. (2005), "Outcomes for children and adolescents after residential treatment: a review of research from 1993 to 2003", Journal of Child and Family Studies, Vol. 14 No. 4, pp. 551-76.

Holden, M.J. (2009), Children and Residential Experiences: Creating Conditions for Change, CWLA, Arlington, VA.

Hughes, D. (2004), Building the Bonds of Attachment: Awakening Love in Deeply Troubled Children, Rowman and Littlefield, Oxford.

Jasper, M. and Rosser, M. (2013), "Reflection and reflective practice", in Rosser, M., Mooney, G.P. and Jasper, M. (Eds), Professional Development, Reflection and Decision-Making in Nursing and Healthcare, Wiley-Blackwell, Chichester, pp. 41-82.

Javnbakht, M., Hejazi, K. and Ghasemi, M. (2009), "Effects of yoga on depression and anxiety in women", Complementary Therapies in Clinical Practice, Vol. 15 No. 2, pp. 102-4, doi: 10.1016/j. ctcp.2009.01.003.

Kennedy, H., Reed, K. and Wamboldt, M. (2013), "Staff perceptions of complementary and alternative therapy integration into a child and adolescent psychiatry program", The Arts in Psychotherapy, Vol. 41 No. 1, pp. 21-6.

Khalsa, S.B. (2004), "Yoga as atherapeutic intervention: a bibliometric analysis of published research studies", Indian Journal of Physiology and Pharmacology, Vol. 48 No. 3, pp. 269-85.

Khalsa, S.B. (2013), "Yoga for psychiatry and mental health: an ancient practice with modern relevance", Indian Journal of Psychiatry, Vol. 55 No. 3, pp. 334-6, available at: www.indianjpsychiatry.org/text.asp?2013/ 55/7/334/116298

Kjellgren, A., Bood, S.A., Axelsson, K., Norlander, T. and Saatcioglu, F. (2007), "Wellness through a comprehensive yogic breathing program - a controlled pilot trial", BMC Complementary and Alternative Medicine, Vol. 7 No. 43, pp. 1-8, doi: 10.1186/1472-6882-7-43. 
Larouche, E., Hudon, C. and Goulet, S. (2015), "Potential benefits of mindfulness-based interventions in mild cognitive impairment and Alzheimer's disease: an interdisciplinary perspective”, Behavioural Brain Research, Vol. 276, January, pp. 199-212.

Lee, B., Bright, C., Svoboda, D., Fakunmoju, S. and Barth, R. (2011), "Outcomes of group care for youth: a review of comparative studies", Research on Social Work Practice, Vol. 21 No. 2, pp. 177-89.

Malathi, A. and Damodaran, A. (1999), "Stress due to exams in medical students: role of yoga", Indian Journal of Pharmacology, Vol. 43 No. 2, pp. 218-24.

Michalsen, A., Grossman, P., Acil, A., Langhorst, J., Ludtke, R., Esch, T., Stefano, G. and Dobos, G. (2005), "Rapid stress reduction and anxiolysis among distressed women as a consequence of a three-month intensive yoga program", Medical Science Monitor, Vol. 11 No. 12, pp. CR555-61, available at: www. medscimonit.com/download/index/idArt/438851

National Audit Office (2014), "Children in care", National Audit Office, available at: www.nao.org.uk/wpcontent/uploads/2014/11/Children-in-care1.pdf (accessed 15 September 2015).

Nyman, A., Josephsson, S. and Isaksson, G. (2012), "Being part of an enacted togetherness: narratives of elderly people with depression”, Journal of Aging Studies, Vol. 26 No. 4, pp. 410-18.

OFSTED (2014), "Children's homes inspections and outcomes", OFSTED, available at: www.gov.uk/ government/statistical-data-sets/childrens-homes-inspection-and-outcomes-july-2014-to-september-2014

Oken, B.S., Zajdel, D., Kishiyama, S., Flegal, K., Dehen, C., Haas, M., Kraemer, D., Lawrence, J. and Leyva, J. (2006), "Randomized controlled six-month trial of yoga in healthy seniors: effects on cognition and quality of life", Alternative Therapies in Health and Medicine, Vol. 12 No. 1, pp. 40-7, available at: www.ncbi.nlm.nih. gov/pmc/articles/PMC1457100/

Paterson, C. and Chapman, J. (2013), "Enhancing skills of critical reflection to evidence learning in professional practice", Physical Therapy in Sport, Vol. 14 No. 3, pp. 133-8, doi: 10.1016/j.ptsp.2013.03.004.

Price, J., Farmer, G., Harris, J., Hope, T., Kennedy, S. and Mayou, R. (2006), "Attitudes of women with chronic pelvic pain to the gynaecological consultation: a qualitative study", BJOG: An International Journal of Obstetrics and Gynaecology, Vol. 113, pp. 446-52.

Rhodes, A. (2015), "Claiming peaceful embodiment through yoga in the aftermath of trauma", Complementary Therapies in Clinical Practice, Vol. 21 No. 4, pp. 247-56.

Rodrigues, V.C. (2004), "Health of children looked after by the local authorities", Public Health, Vol. 118 No. 5 , pp. 370-6.

Sahasi, G., Mohan, D. and Kacker, C. (1989), "Effectiveness of yogic techniques in the management of anxiety”, Journal of Personal Clinical Studies, Vol. 5 No. 1, pp. 51-5.

Secker, J., Hacking, S., Kent, L., et al. (2009), "Development of a measure of social inclusion for arts and mental health project participants", Journal of Mental Health, Vol. 18 No. 1, pp. 65-72.

Sharma, I., Azmi, S.A. and Settiwar, R.M. (1991), "Evaluation of the effect of pranayama in anxiety state", Alternative Medicine, Vol. 3, pp. 227-35.

Simpson, E.L. and House, A.O. (2003), "User and carer involvement in mental health services: from rhetoric to science", The British Journal of Psychiatry: The Journal of Mental Science, Vol. 183 No. 2, pp. 89-91.

Smith, C., Hancock, H., Blake-Mortimer, J. and Eckert, K. (2007), "A randomized comparative trial of yoga and relaxation to reduce stress and anxiety", Complementary Therapies in Medicine, Vol. 15 No. 2, pp. 77-83, doi: 10.1016/j.ctim.2006.05.001.

Tennant, R., Hiller, L., Fishwick, R., Platt, S., Joseph, S., Weich, S., Parkinson, J., Secker, J. and StewartBrown, S. (2007), "The Warwick-Edinburgh Mental-being Scale (WEMWBS): development and UK validation", Health and Quality of Live Outcomes, Vol. 5 p. 63, available at: www.hglo.com/content/5/1/63

Thomas, M. and Johnson, M. (2008), "New advances in understanding sensitive periods in brain development", Association for Psychological Science, Vol. 17 No. 1, pp. 132-41.

Vahia, N.S., Doongaji, D.R., Jeste, D.V., Kapoor, S., Ardhapurkar, I. and Nath, R. (1973), "Further experience with therapy based on concepts of Patanjali in the treatment of psychiatric disorders", Indian Journal of Psychiatry, Vol. 15 No. 1, pp. 32-7. 
Varambally, S. and Gangadhar, B. (2012), "Yoga: a spiritual practice with therapeutic value in psychiatry", Asian Journal of Psychiatry, Vol. 5 No. 2, pp. 186-9, doi: 10.1016/j.ajp.2012.05.003.

Veage, S., Ciarrochi, J., Deane, F., Andresen, R., Oades, L. and Crowe, T. (2014), "Value congruence, importance and success and in the workplace: links with well-being and burnout amongst mental health practitioners", Journal of Contextual Behavioral Science, Vol. 3 No. 4, pp. 258-64.

Vorkapic, C. and Range, B. (2014), "Reducing the symptomatology of panic disorder: the effects of a yoga program alone and in combination with cognitive-behavioral therapy", Frontiers in Psychiatry, Vol. 5 No. 177, pp. 1-7.

\section{Authors affiliations}

Elvira Perez Vallejos is a Senior Research Fellow at The University of Nottingham, Nottingham, UK. Mark John Ball is an Edge of Care Hub Manager at the Children and Families, Nottingham City Council, Nottingham, UK.

Poppy Brown is based at the School of Medicine, The University of Nottingham, Nottingham, UK.

David Crepaz-Keay is a Department Head at the Mental Health Foundation, London, UK.

Emily Haslam-Jones is based at Yoganova, Nottingham, UK.

Paul Crawford is based at the Faculty of Medicine and Health Sciences, The University of Nottingham, Nottingham, UK.

\section{Appendix 1}

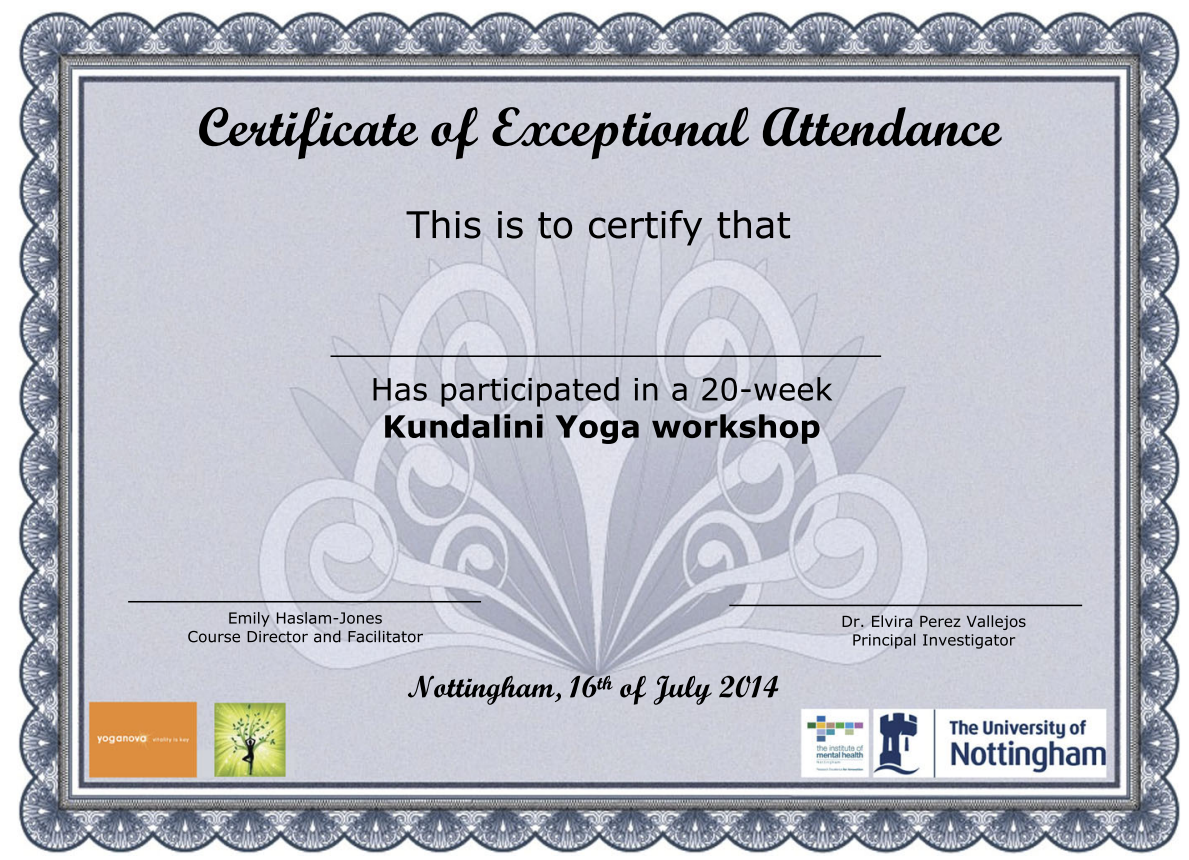




\section{The Short Warwick-Edinburgh \\ Mental Well-being Scale \\ (SWEMWBS)}

Below are some statements about feelings and thoughts.

Please tick the box that best describes your experience of each over the last 2 weeks

\begin{tabular}{|l|l|l|l|l|l|}
\hline \multicolumn{1}{|c|}{ STATEMENTS } & $\begin{array}{l}\text { None } \\
\text { of the } \\
\text { time }\end{array}$ & $\begin{array}{l}\text { Rarely } \\
\begin{array}{l}\text { I've been feeling optimistic about the } \\
\text { future }\end{array}\end{array}$ & $\begin{array}{l}\text { Some } \\
\text { of the } \\
\text { time }\end{array}$ & Often & $\begin{array}{c}\text { All of } \\
\text { the } \\
\text { time }\end{array}$ \\
\hline I've been feeling useful & & & & & \\
\hline I've been feeling relaxed & & & & & \\
\hline I've been dealing with problems well & & & & & \\
\hline I've been thinking clearly & & & & & \\
\hline $\begin{array}{l}\text { I've been feeling close to other } \\
\text { people }\end{array}$ & & & & & \\
\hline $\begin{array}{l}\text { l've been able to make up my own } \\
\text { mind about things }\end{array}$ & & & & & \\
\hline
\end{tabular}

"Short Warwick Edinburgh Mental Well-being Scale (SWEMWBS) (c) NHS Health Scotland, University of Warwick and University of Edinburgh, 2007, all rights reserved." 
Appendix 3

\section{About you and other people}

The statements below are about relationships with other people. Please tick the box that best describes your experience over the last month

\begin{tabular}{|l|l|l|l|l|}
\hline \multicolumn{1}{|c|}{ Statements } & Not at all & \multicolumn{1}{c|}{$\begin{array}{c}\text { Not } \\
\text { particularly }\end{array}$} & Yes a bit & $\begin{array}{c}\text { Yes } \\
\text { definitely }\end{array}$ \\
\hline $\begin{array}{l}\text { I have friends I see or talk to } \\
\text { every week }\end{array}$ & & & & \\
\hline $\begin{array}{l}\text { I have learnt something about } \\
\text { other people's cultures }\end{array}$ & & & & \\
\hline I have been to new places & & & \\
\hline $\begin{array}{l}\text { I have felt accepted by my } \\
\text { friends }\end{array}$ & & & & \\
\hline $\begin{array}{l}\text { I have felt accepted by my } \\
\text { family }\end{array}$ & & & & \\
\hline $\begin{array}{l}\text { I have felt accepted by my } \\
\text { neighbours }\end{array}$ & & & & \\
\hline $\begin{array}{l}\text { I have been out socially with } \\
\text { friends }\end{array}$ & & & & \\
\hline $\begin{array}{l}\text { I have done some cultural } \\
\text { activities (e.g. gone to a } \\
\text { library, museum, gallery, } \\
\text { theatre, concert) }\end{array}$ & & & & \\
\hline $\begin{array}{l}\text { I have felt clear about my } \\
\text { rights }\end{array}$ & & & & \\
\hline $\begin{array}{l}\text { I have felt free to express my } \\
\text { beliefs (for example political or } \\
\text { religious beliefs) }\end{array}$ & & & & \\
\hline $\begin{array}{l}\text { I have felt that I am playing a } \\
\text { useful part in society }\end{array}$ & & & & \\
\hline $\begin{array}{l}\text { I have felt that what I do is } \\
\text { valued by others }\end{array}$ & & & & \\
\hline
\end{tabular}


Please read this carefully:

We should like to know if you have had any medical complaints, and how your health has been in general, over the past few weeks. Please answer ALL the questions simply by underlining the answer which you think most nearly applies to you. Remember that we want to know about present and recent complaints, not those you had in the past. It is important that you try to answer ALL the questions.

Thank you for your co-operation.

\begin{tabular}{|c|c|c|c|c|}
\hline $\begin{array}{l}\text { HAVE YOU RECENTLY: } \\
1 \text { - been able to concentrate on } \\
\text { whatever you're doing? }\end{array}$ & $\begin{array}{l}\text { Better } \\
\text { than usual }\end{array}$ & $\begin{array}{l}\text { Same } \\
\text { As usual }\end{array}$ & $\begin{array}{l}\text { Less } \\
\text { than usual }\end{array}$ & $\begin{array}{l}\text { Much less } \\
\text { than usual }\end{array}$ \\
\hline $\begin{array}{l}2 \text { - lost much sleep over } \\
\text { worry? }\end{array}$ & $\begin{array}{l}\text { Not } \\
\text { at all }\end{array}$ & $\begin{array}{l}\text { No more } \\
\text { than usual }\end{array}$ & $\begin{array}{l}\text { Rather } \\
\text { more } \\
\text { than usual }\end{array}$ & $\begin{array}{l}\text { Much more } \\
\text { than usual }\end{array}$ \\
\hline $\begin{array}{l}3 \text { - felt that you are playing a } \\
\text { useful part in things? }\end{array}$ & $\begin{array}{l}\text { More so } \\
\text { than usual }\end{array}$ & $\begin{array}{l}\text { Same } \\
\text { As usual }\end{array}$ & $\begin{array}{l}\text { Less } \\
\text { useful } \\
\text { than usual }\end{array}$ & $\begin{array}{l}\text { Much less } \\
\text { useful }\end{array}$ \\
\hline $\begin{array}{l}4 \text { - felt capable of making } \\
\text { decisions about things? }\end{array}$ & $\begin{array}{l}\text { More so } \\
\text { than usual }\end{array}$ & $\begin{array}{l}\text { Same } \\
\text { As usual }\end{array}$ & $\begin{array}{l}\text { Less so } \\
\text { than usual }\end{array}$ & $\begin{array}{l}\text { Much less } \\
\text { capable }\end{array}$ \\
\hline $\begin{array}{l}5 \text { - felt constantly under } \\
\text { strain? }\end{array}$ & $\begin{array}{l}\text { Not } \\
\text { at all }\end{array}$ & $\begin{array}{l}\text { No more } \\
\text { than usual }\end{array}$ & $\begin{array}{l}\text { Rather } \\
\text { more } \\
\text { than usual }\end{array}$ & $\begin{array}{l}\text { Much more } \\
\text { than usual }\end{array}$ \\
\hline $\begin{array}{l}6 \text { - felt you couldn't overcome } \\
\text { difficulties? }\end{array}$ & $\begin{array}{l}\text { Not } \\
\text { at all }\end{array}$ & $\begin{array}{l}\text { No more } \\
\text { than usual }\end{array}$ & $\begin{array}{l}\text { Rather } \\
\text { more } \\
\text { than usual }\end{array}$ & $\begin{array}{l}\text { Much more } \\
\text { than usual }\end{array}$ \\
\hline $\begin{array}{l}7 \text { - been able to enjoy your } \\
\text { normal day-to-day activities? }\end{array}$ & $\begin{array}{l}\text { More so } \\
\text { than usual }\end{array}$ & $\begin{array}{l}\text { Same } \\
\text { As usual }\end{array}$ & $\begin{array}{l}\text { Less so } \\
\text { than usual }\end{array}$ & $\begin{array}{l}\text { Much less } \\
\text { than usual }\end{array}$ \\
\hline $\begin{array}{l}8 \text { - been able to face up to your } \\
\text { problems? }\end{array}$ & $\begin{array}{l}\text { More so } \\
\text { than usual }\end{array}$ & $\begin{array}{l}\text { Same } \\
\text { As usual }\end{array}$ & $\begin{array}{l}\text { Less able } \\
\text { than usual }\end{array}$ & $\begin{array}{l}\text { Much less } \\
\text { able } \\
\text { than usual }\end{array}$ \\
\hline $\begin{array}{l}9 \text { - been feeling unhappy and } \\
\text { depressed? }\end{array}$ & $\begin{array}{l}\text { Not } \\
\text { at all }\end{array}$ & $\begin{array}{l}\text { No more } \\
\text { than usual }\end{array}$ & $\begin{array}{l}\text { Rather } \\
\text { more } \\
\text { than usual }\end{array}$ & $\begin{array}{l}\text { Much more } \\
\text { than usual }\end{array}$ \\
\hline $\begin{array}{l}10 \text { - been losing confidence in } \\
\text { yourselr? }\end{array}$ & $\begin{array}{l}\text { Not } \\
\text { at all }\end{array}$ & $\begin{array}{l}\text { No more } \\
\text { than ustual }\end{array}$ & $\begin{array}{l}\text { Rather } \\
\text { more } \\
\text { than usual }\end{array}$ & $\begin{array}{l}\text { Much more } \\
\text { than usual }\end{array}$ \\
\hline $\begin{array}{l}11 \text { - been thinking of yourself } \\
\text { as a worthless person? }\end{array}$ & $\begin{array}{l}\text { Not } \\
\text { at all }\end{array}$ & $\begin{array}{l}\text { No more } \\
\text { than usual }\end{array}$ & $\begin{array}{l}\text { Rather } \\
\text { more } \\
\text { than usual }\end{array}$ & $\begin{array}{l}\text { Much more } \\
\text { than usual }\end{array}$ \\
\hline $\begin{array}{l}12 \text { - been feeling reasonably } \\
\text { happy, all things considered? }\end{array}$ & $\begin{array}{l}\text { More so } \\
\text { than usual }\end{array}$ & $\begin{array}{l}\text { About same } \\
\text { as usual }\end{array}$ & $\begin{array}{l}\text { Less so } \\
\text { than usual }\end{array}$ & $\begin{array}{l}\text { Much less } \\
\text { than usual }\end{array}$ \\
\hline
\end{tabular}




\section{APPENDIX A}

Date of interview:

Interviewer:

Subject Initials:

Treatment or Control group

Introduction:

- Thank you for coming in for this interview

- Purpose:

To explore how you think about yoga. Hear your experiences of the program. Learn more about your experience that we may have missed on the questionnaires

- Confidentiality:

Your answers will never be linked to your name. You will remain anonymous. Only study staff will have access to the recordings and transcripts.

- These interviews usually take about 30 minutes.

- If there are any questions that you do not want to answe please let me know.

- Do you mind if I tape the interview? Yes/No (turn on recorder)

\section{Experience-narrative of classes:}

- Please tell me how the yoga classes were for you? (If no spontaneous narrative: Please tell me any stories from the yoga classes

- What parts of the classes did you like? (Probe: time-in, breathing exercises, postures, games, partner poses, rest pose)

- Is there anything you would change?

- Did you learn anything new in the yoga classes?

- Is there anything you would like to learn more about?

2. Have you seen any changes in your life because of the yoga?
- (Probe if not mentioned one at a time, have you seen any changes?)

- How about your sleep, mood, anxiety about school, behaviors like paying attention?

- Have you noticed any changes in your health?

- Have you noticed any changes in relationships-how you feel about people and interact with them, or how they interact with you?

- Have you used any of the tools that you learned in yoga class in other areas of your life?

- Have you seen any changes in your friends' behavior that might be due to the yoga?

- Some people who do yoga say that practicing it changes other behaviors too. Do you think that this is true?”

- How do you think yoga works?

3. Administration-Joining the study:

- How do you feel now about having joined the study?

- How do you feel about the questionnaire packet? Length, time to complete, etc.

- Did you understand the questions being asked ... if No what didn't you understand?

- Are there any changes should we make for next time?

4. Closure:

- If it were possible would you like to continue yoga classes?

- What would you change for next time?

- Is there anything else you'd like to say about this?

- Do you have any questions?

- How was this interview for you?

5. Observational notes (interviewer: Please record any body language, other cues):

180 EXPLORE May/June 2013, Vol. 9, No. 3

\section{About the authors}

Elvira Perez Vallejos is a Senior Research Fellow at the Institute of Mental Health, The University of Nottingham, interested in developing interventions to improve outcomes among children in care and their carers. Elvira Perez Vallejos is the corresponding author and can be contacted at: elvira.perez@nottingham.ac.uk

Mark John Ball works in the Edge of Care Hub (Nottingham City Council) and his team provide support to families to avoid social services interventions and child removal from family.

Poppy Brown is a third year Medical Student at the Liverpool University interested in promoting well-being and health awareness among children in care. 
David Crepaz-Keay is a Head of Empowerment and Social Inclusion at the Mental Health Foundation interested in creating strong and effective voices for people directly affected by mental ill-health.

Emily Haslam-Jones is an experienced Yoga Teacher who has worked with highly traumatised children in war conflicts (e.g. Nepal). She interested in understanding the embodied effects of trauma and how movement and meditation can alleviate suffering.

Paul Crawford is the First Professor in Health Humanities interested in understanding the concept of mutual recovery.

For instructions on how to order reprints of this article, please visit our website:

www.emeraldgrouppublishing.com/licensing/reprints.htm

Or contact us for further details: permissions@emeraldinsight.com 